\title{
LYAPUNOV INEQUALITIES FOR TWO KINDS OF HIGHER-ORDER MULTI-POINT FRACTIONAL BOUNDARY VALUE PROBLEMS
}

\section{DEXIANG MA}

Abstract. We obtain Lyapunov inequality and Hartman-Wintner-type inequality for two higherorder multi-point fractional boundary value problems. The technique of order-reduction and the properties of Green's function are important to our results. As applications, we discuss the eigenvalue problem and the real zeros for Mittag-Leffler function.

Mathematics subject classification (2010): 26A33, 26D10, 33E12, 34A08.

Keywords and phrases: Caputo fractional derivative; Multi-point; Green's function; Lyapunov inequality; Eigenvalue problem; Mittag-Leffler function.

\section{REFERENCES}

[1] A. M. Lyapunov, Probléme général de la stabilité du mouvement, Annales de la Faculté des sciences de Toulouse: Mathématiques, 9 (1907), 203-474.

[2] A. Wintner, On the non-existence of conjugate points, Amer. J. Math. 73 (1951), 368-380.

[3] P. Hartman And A. Wintner, On an oscillation criterion of Lyapunov Amer. J. Math. 73 (1951), $885-890$.

[4] A. TiRYAKI, Recent developments of Lyapunov-type inequalities, Adv. Dyn. Syst. Appl. 5: 2 (2010), 231-248.

[5] R. P. AgARwal AND A. ÖZBeKLeR, Lyapunov type inequalities for second order forced mixed nonlinear impulsive differential equations, Appl. Math. Comput. 282 (2016), 216-225.

[6] R. P. AgARWAL AND A. ÖZBEKLER, Lyapunov type inequalities for second order sub and superhalf-linear differential equations, Dynam. Syst. Appl. 24 (2015), 211-220.

[7] R. P. AGARWAL AND A. ÖZBEKLER, Lyapunov type inequalities for even order differential equations with mixed nonlinearities, J. Inequal. Appl. 2015: 142 (2015), 1-10.

[8] R. A. C. FERreira, A Lyapunov-type inequality for a fractional boundary value problem, Fract. Calc. Appl. Anal. 16: 4 (2013), 978-984.

[9] R. A. C. Ferreira, On a Lyapunov-type inequality and the zeros of a certain Mittag-Leffler function, J. Math. Anal. Appl. 412: 2 (2014), 1058-1063.

[10] M. JLELI AND B. S AMET, Lyapunov-type inequalities for a fractional differential equation with mixed boundary conditions, Math. Inequal. Appl. 18: 2 (2015), 443-451.

[11] M. JLeli, L. RAGOUB AND B. SAMET, Lyapunov-type inequality for a fractional differential equation under a Robin boundary conditions, J. Func. Spaces 2015, Article number 468536 (2015), 1-5.

[12] J. RoNG AND C. Z. BAI, Lyapunov-type inequality for a fractional differential equation with fractional boundary conditions, Adv. Differ. Equ. 82: 1 (2015), 1-10.

[13] Y. Y. WANG, S. L. LIANG AND C. X. XIA, A Lyapunov-type inequalities for a fractional differential equation under sturm-liouville boundary conditions, Math. Inequal. Appl. 2016, Article number mia5033 (2016), 1-10.

[14] R. A. C. FERREIRA, Lyapunov-type inequalities for some sequential fractional boundary value problems, Adv. Dyn. Syst. Appl. 11: 1 (2016), 33-43.

[15] R. P. AgARwal AND A. ÖZBeKLeR, Lyapunov-type inequalities for mixed nonlinear RiemannLiouville fractional differential equations with a forcing term, J. Comput. Appl. Math. (2016), http://dx.doi.org/10.1016/j.cam.2016.10.009. 
[16] A. Chidoun And D. F. M. Torresb, A generalized Lyapunov inequality for a fractional boundary value problem, J. Comput. Appl. Math. (2016), DOI.org/10.1016/ j.cam.2016.03.035.

[17] D. O'REgAN AND B. SAMET, Lyapunov-type inequalities for a class of fractional differential equations, J. Inequal. Appl. 2015: 247 (2015), 1-10.

[18] N. Arifi, I. Altun, M. Jleli, A. Lashin AND B. SAmet, Lyapunov-type inequalities for a fractional p-Laplacian equation, J. Inequal. Appl. 2016: 189 (2016), 1-11.

[19] I. CABRERA, K. SADARANGANi AND B. SAMET, Hartman-Wintner-type inequalities for a class of nonlocal fractional boundary value problems, Math. Meth. Appl. Sci. 2016, DOI: 10.1002/mma.3972 (2016), 1-8.

[20] M. JLELI, M. KiRANE AND B. SAMET, Lyapunov-type inequalities for fractional partial differential equations, App. Math. Lett. 66 (2017), 30-39.

[21] M. JLELI, M. KIRANE AND B. SAMET, Hartman-Wintner-Type inequality for a fractional boundary value problem via a fractional derivative with respect to another function, Discrete Dyn. Nat. Soc. 2017 (2017).

[22] A. A. Kilbas, H. M. SRivastava And J. J. Trujillo, Theory and applications of fractional differential equations, Amsterdam: Elsevier; 2006.

[23] I. Podlubny, Fractional differential equation, San Diego, CA: Academic Press; 1999.

[24] A. A. Kilbas, M. Rivero, L. Rodriguez-Germa And J. J. Trujillo, Caputo linear fractional differential equation, IFAC Proceedings 39: 11 (2010), 52-57. 